\title{
INFECÇÕES RESPIRATÓRIAS VIRAIS EM PACIENTES IMUNODEPRIMIDOS
}

\author{
RESPIRATORY VIRAL INFECTIONS IN IMMUNOCOMPROMISED PATIENTS
}

Otávio A. L. Cintra'; Eurico Arruda²

\begin{abstract}
${ }^{1}$ Médico Assistente do Departamento de Puericultura e Pediatria do Hospital das Clínicas e ${ }^{2}$ Professor de Virologia do Departamento de Parasitologia, Microbiologia e Imunologia. Faculdade de Medicina de Ribeirão Preto da Universidade de São Paulo (FMRP-USP). Correspondência: Otávio Augusto Leite Cintra, Departamento de Puericultura e Pediatria da Faculdade de Medicina de Ribeirão Preto da USP. Av. Bandeirantes, 3900 - CEP: 14051-970 - Ribeirão Preto, SP, Brazil. Fone/Fax: (0xx)(16)633-0136. e-mail: oacintra@keynet.com.br
\end{abstract}

CINTRA OAL \& ARRUDA E. Infecções respiratórias virais em pacientes imunodeprimidos. Medicina, Ribeirão Preto, 32: 129-137, abr./jun. 1999.

RESUMO: As infecções agudas, causadas por vírus respiratórios são as mais freqüentes da humanidade. Os vírus respiratórios comuns vêm sendo, progressivamente, mais implicados como causa de infecções respiratórias potencialmente graves em pacientes imunodeprimidos. O presente trabalho faz uma breve revisão dos aspectos clínicoepidemiológicos de infecções respiratórias virais, enfatizando sua importância em pacientes com função imune comprometida.

UNITERMOS: Infecções Respiratórias. Imunodeficiência. HIV.

\section{INTRODUÇÃO}

As infecções respiratórias agudas (IRA) são as doenças infecciosas mais freqüentes em seres humanos e os vírus respiratórios (Tabela I) são os mais freqüentes agentes etiológicos de IRA ${ }^{(1,2)}$. Esses agentes têm grande variedade antigênica, distribuição universal e acometem pessoas em todas as faixas etárias, podendo causar várias síndromes clínicas, com acometimento tanto de trato respiratório superior (IRA alta), quanto inferior (IRA baixa) (Tabela II) ${ }^{(3 ; 4)}$. Nos países em desenvolvimento, os tipos de IRA representam uma causa importante de morbidade e são uma das principais causas de mortalidade. Estima-se que tais infecções causem, em escala global, mais de quatro milhões de óbitos anuais entre crianças ${ }^{(5)}$.

Apesar de acometerem pessoas de todas as idades, as características clínicas dos tipos de IRA virais podem diferir conforme a faixa etária ${ }^{(3)}$. Crianças com menos de dois (02) anos de idade e idosos apresen- tam IRA baixa com maior freqüência e também maior mortalidade por IRA relativamente às demais faixas etárias ${ }^{(3 ; 4)}$. Nessas mesmas faixas etárias, também, são mais comuns as infecções bacterianas secundárias, principalmente otite média aguda (OMA), sinusite e pneumonia ${ }^{(3,4)}$. Pessoas que apresentam doenças de base, tais como cardiopatias e pneumopatias, também apresentam doenças mais graves, quando infectadas por vírus respiratórios ${ }^{(4)}$.

Imunodeficiências primárias têm sido associadas a maior gravidade deIRAs ${ }^{(6,7,8)}$. Pacientes submetidos a tratamento que acarreta imunodepressão, tais como tratamento antineoplásico e transplantes, também estão sujeitos a maior gravidade de IRA vi$\mathrm{ral}^{(9)}$. Os diferentes tipos de IRA, de etiologia viral, em pacientes com imunodeficiência, têm sido relativamente pouco estudados ${ }^{(9)}$. Como as opções terapêuticas para tratamento antiviral vêm se tornando mais freqüentes, há renovado interesse em diagnóstico precoce $^{(3 ; 9)}$. Melhores técnicas de diagnóstico virológico 


\begin{tabular}{|c|c|c|c|c|c|}
\hline \multicolumn{6}{|c|}{ Tabela I - Vírus respiratórios humanos comuns } \\
\hline Vírus & Família & Gênero & Tipos & Ácido nucléico & Doença respiratória \\
\hline $\mathrm{VSR}^{*}$ & Paramyxoviridae & Pneumovirus & $\begin{array}{l}2 \text { subgrupos } \\
(A \text { e } B)\end{array}$ & RNA (-) & $\begin{array}{l}\text { IVAS }{ }^{* *} ; \text { bronquiolite; } \\
\text { pneumonia }\end{array}$ \\
\hline Parainfluenza & Paramyxoviridae & $\begin{array}{l}\text { Paramyxovirus } \\
\text { (tipos } 1 \text { e } 3 \text { ) } \\
\text { Rubulavirus } \\
\text { (tipos } 2 \text { e } 4 \text { ) }\end{array}$ & $4(1,2,3$ e 4$)$ & RNA (-) & $\begin{array}{l}\text { IVAS; crupe; } \\
\text { pneumonia; } \\
\text { bronquiolite }\end{array}$ \\
\hline Influenza & Orthomyxoviridae & Influenzavirus & $\begin{array}{l}3(\mathrm{~A}, \mathrm{~B} \text { e } \mathrm{C}) \mathrm{com} \\
\text { muitos subtipos }\end{array}$ & $\begin{array}{l}\text { RNA (-) } \\
\text { segmentado }\end{array}$ & $\begin{array}{l}\text { IVAS; síndrome de } \\
\text { influenza; pneumonia; } \\
\text { crupe }\end{array}$ \\
\hline Adenovírus & Adenoviridae & Mastadenovirus & $>45$ & DNA & $\begin{array}{l}\text { IVAS; faringite; } \\
\text { pneumonia; } \\
\text { conjuntivite }\end{array}$ \\
\hline Rinovírus & Picornaviridae & Rhinovirus & $>100$ & RNA (+) & IVAS \\
\hline Coronavírus & Coronaviridae & Coronavirus & $2(\mid$ e II) & RNA (+) & IVAS \\
\hline
\end{tabular}

*VSR: vírus sincicial respiratório.

**IVAS: Infecção das vias aéreas superiores.

Adaptado de McIntosh, $\mathrm{K}^{10}$.

e maior interesse na detecção de vírus respiratórios resultaram em maior atenção a esses agentes e à pesquisa do seu papel como causa de IRA em pacientes com câncer e transplantados ${ }^{(3 ; 9)}$. O objetivo do presente artigo é fazer uma breve revisão das infecções causadas por esses agentes em pacientes imunossuprimidos, enfocando, principalmente, suas características clínicas e epidemiológicas e as possíveis abordagens para sua terapêutica e prevenção.

\section{EPIDEMIOLOGIA DAS INFECÇÕES RESPI- RATÓRIAS AGUDAS VIRAIS EM PACIEN- TES COM IMUNODEPRESSÃO}

Em climas temperados, a sazonalidade é uma característica epidemiológica marcante dos vírus respiratórios, especialmente VSR, influenza e rinovírus ${ }^{(2,4)}$. Já os vírus parainfluenza (PIV) e adenovírus ocorrem durante todo o ano e causam surtos esporádicos ${ }^{(2)}$. Apesar de as infecções por coronavírus ocorrerem mais no inverno, em climas temperados, a sazonalidade desses agentes não está completamente definida ${ }^{(4)}$.

Whimbley et al. ${ }^{(9)}$, no "M.D. Anderson Cancer Center" (MDACC) da Universidade do Texas, Houston - Texas - EUA, observaram que os padrões de sazonalidade dos vírus respiratórios, em geral, se mantêm em pacientes adultos imunodeprimidos por câncer. Em três (03) anos de observação, esses autores isolaram vírus respiratórios em $27,1 \%$ dos pacientes que apresentavam quadros respiratórios agudos, utilizando lavados nasais e "swabs" de orofaringe. Dentre os agentes isolados, o VSR foi o mais freqüente $(31 \%)$, seguido de perto por picornavírus (28\%, sendo $90 \%$ deles rinovírus) e, com menor freqüência, os vírus influenza (18\%), parainfluenza (15\%) e adenovírus (8\%).

Tabela II - Importância das infecções respiratórias agudas por vírus

Infecções mais comuns em seres humanos

Causas importantes de morbidade, inclusive de doenças graves, hospitalizações e óbitos, principalmente em crianças pequenas, idosos e pacientes com imunodepressão

Principais fatores predisponentes para otite média aguda, sinusite e pneumonia bacteriana

Uma das principais causas de insuficiência respiratória aguda em pessoas com doenças pulmonares (asma, doença pulmonar crônica) e cardíacas (cardiopatias congênitas, insuficiência cardíaca)

Causas importantes de falta ao trabalho e à escola

Adaptado de Couch, RB et al. (3) 
Arola el al. ${ }^{(11)}$ avaliaram a ocorrência de vírus respiratórios em crianças com febre durante tratamento para câncer, utilizando os métodos de isolamento viral, detecção direta de antígenos e sorologia, em um período de dezessete (17) meses. Eles foram capazes de identificar um agente viral em $37 \%$ dos casos, sendo o rinovírus o agente mais freqüente $(17 \%)$, seguido pelo VSR (8\%).

Bowden $^{(12)}$ examinou, retrospectivamente, a freqüência de vírus respiratórios em pacientes submetidos a transplante de medula óssea (TMO) durante oito (08) anos, no Fred Hutchinson Cancer Research Center (FHCRC) de Seattle, Washington - EUA. Dentre os vírus isolados, VSR foi o mais freqüente (35\%), seguido por vírus parainfluenza (30\%), rinovírus $(25 \%)$ e influenza (11\%).

Em pacientes submetidos a transplantes de órgãos ${ }^{(13)}$, VSR, parainfluenza, influenza e adenovírus também são os agentes encontrados com maior freqüência. A maior incidência de infecção por tais agentes foi observada em pacientes submetidos a transplante de pulmão, com freqüência de até $21 \%$.

Quanto aos pacientes infectados pelo vírus da imunodeficiência humana (HIV), apesar de gravemente imunossuprimidos, eles não apresentam maior freqüência nem maior gravidade de infecções por vírus respiratórios $^{(10 ; 14)}$. Há casos relatados de formas graves de infecção por vírus influenza ${ }^{(15)}$, adenovírus ${ }^{(16)}$ e VSR ${ }^{(17)}$ nesses pacientes, porém, dois estudos sobre VSR, em crianças infectadas pelo HIV, não de- monstraram nelas maior gravidade de infecções por $\mathrm{VSR}^{(18,19)}$. No entanto, ainda é muito pequeno o número de estudos longitudinais, abordando outros vírus respiratórios em pacientes com infecção por HIV e não é sabido se há maior freqüência de IRA nesses pacientes $^{(13)}$.

A Tabela III resume os principais resultados dos levantamentos de IRAs virais em dois grandes centros de tratamento de câncer nos Estados Unidos e do Grupo Europeu para TMO, que congrega diversas instituições na Europa.

\section{VÍRUS SINCICIAL RESPIRATÓRIO (VSR)}

O VSR é o principal agente de IRA baixa em crianças menores de um (01) ano de idade e é a causa mais freqüiente de bronquiolite. Em crianças internadas por um quadro de IRA viral, o VSR foi o agente encontrado com maior freqüência ${ }^{(4)}$.

O VSR também foi o vírus respiratório isolado com maior freqüência em pacientes com leucemia $(18 \%)^{(20)}$ e submetidos a TMO $(35 \%)^{(21)}$. Nesses pacientes, o VSR apresentou características peculiares, descritas a seguir, conforme os estudos realizados no "M.D. Anderson Cancer Center" (MDACC) $)^{(9,20,21)}$ e "Fred Hutchinson Cancer Research Center" (FHRCC) ${ }^{(12)}$.

Transplante de Medula Óssea (TMO). O VSR causou IRA nesses pacientes, especialmente durante o seu período epidêmico na comunidade. O quadro clínico é semelhante ao observado em crianças

\begin{tabular}{|c|c|c|c|c|}
\hline \multirow{2}{*}{ Vírus } & \multicolumn{2}{|c|}{ MDACC } & \multirow{2}{*}{ FHCRC(12) TMO } & \multirow{2}{*}{ EGBMT $^{(22)}$ TMO } \\
\hline & leucemia + $\mathrm{TMO}^{(9)}$ & $\mathrm{TMO}^{(21)}$ & & \\
\hline VSR & $56(31)^{\star}$ & $33 \quad(51)$ & $44 \quad(34)$ & $8 \quad(20)$ \\
\hline Vírus parainfluenza & $28 \quad(15)$ & $6(9)$ & $38 \quad(30)$ & $8 \quad(20)$ \\
\hline 1 & 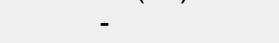 & & 18 & \\
\hline 2 & - & - & 4 & 2 \\
\hline 3 & - & - & 16 & 5 \\
\hline Não tipado & - & - & - & 1 \\
\hline Picornavírus & $52 \quad(28)$ & $10 \quad(15)$ & $31 \quad(24)$ & - \\
\hline Vírus Influenza & $33 \quad(18)$ & 12 (19) & 14 (12) & $15(40)$ \\
\hline$A$ & - & - & 12 & 10 \\
\hline$B$ & - & - & 2 & 5 \\
\hline Adenovírus & $14 \quad(8)$ & $4 \quad(6)$ & - & $8 \quad(20)$ \\
\hline TOTAL & $183(100)$ & $65 \quad(100)$ & $127 \quad(100)$ & $39 \quad(100)$ \\
\hline
\end{tabular}

MDACC: M.D. Anderson Cancer Center; FHCRC: Fred Hutchinson Cancer Research Center; EGBMT: European Group for Blood and Marrow Transplantation.

TMO: transplante de medula óssea

* Número (\%) de pacientes com infecção pelos vírus e documentada. 
imunocompetentes, começando com uma infecção das vias aéreas superiores (IVAS) e evoluindo para acometimento do trato respiratório inferior. A frequiência de evolução para pneumonia foi maior nos pacientes pré-transplante, no entanto, a mortalidade foi semelhante nos pacientes pré e pós-transplante. $\mathrm{O}$ risco de pneumonia também foi associado ao tempo após o transplante, tendo sido mais freqüente naqueles com tempo inferior a um (01) mês pós-transplante. $\mathrm{O}$ uso de ribavirina por aerossol pareceu ser benéfico, quando utilizado antes do início da pneumonia. Já a ribavirina endovenosa não foi eficaz no tratamento de pneumonia por $\operatorname{VSR}^{(23)}$.

Em dez (10) casos autopsiados, de pacientes que morreram por pneumonia por VSR, características histopatológicas e imunoistoquímicas confirmaram o diagnóstico de infecção invasiva por VSR em todos os casos, e, em apenas três (03) pacientes, outro agente infeccioso foi concomitantemente detectado.

Leucemia. A epidemiologia e o quadro clínico de infecção por VSR, em pacientes com leucemia, têm os mesmos padrões clínicos descritos para os pacientes submetidos a TMO. A frequiência de progressão de IVAS para pneumonia foi consideravelmente alta nos pacientes com mielossupressão (contagem de neutrófilos $\leq 500$ células $/ \mathrm{ml}$ ), nos quais aconteceu em 15/21 (71\%), contra $2 / 10(20 \%)$ daqueles sem mielossupressão. Da mesma forma, a mortalidade foi maior nos primeiros, com $53 \%$ de óbitos, contra nenhum óbito nos pacientes sem mielossupressão. A terapêutica precoce com ribavirina por aerossol, associada a imunoglobulina endovenosa não específica para o VSR, foi eficaz em oito (08) pacientes, quando iniciada antes do quadro de insuficiência respiratória estar instalado. Em contrapartida, $89 \%$ dos pacientes foram a óbito, quando esta terapêutica foi iniciada tardiamente.

No estudo de Arola et al. ${ }^{(11)}$ entre crianças em tratamento para câncer, o VSR foi encontrado em 6/75 (8\%) dos episódios de doença febril, e 4/6 (67\%) das infecções aconteceram em crianças não leucopênicas.

Pacientes infectados pelo HIV. Em crianças infectadas pelo HIV, dois estudos avaliaram a infecção pelo VSR. Chandwani et al. ${ }^{(18)}$, acompanharam dez (10) crianças infectadas por HIV e observaram menor freqüência de casos de bronquiolite, mas constataram um tempo prolongado de excreção viral em três (03) pacientes, que eliminaram o vírus por trinta (30) a noventa (90) dias. King Jr. et al. ${ }^{(19)}$ acompanharam um grupo de crianças infectadas pelo HIV, comparando-as com um grupo de crianças não infectadas por HIV. Estes autores observaram dados semelhantes aos de Chandwani, porém houve tendência para maior frequiência de infecção por VSR nas crianças infectadas por HIV.

Quanto ao diagnóstico do VSR, Englund et al. ${ }^{(24)}$ compararam um teste para detecção rápida do antígeno de VSR por EIA (Directigen - Becton \& Dickson) com o isolamento do vírus, em adultos imunodeprimidos com quadro de IRA e em crianças imunocompetentes com IRA. Os autores observaram que a detecção de VSR por este método, no lavado nasal de pacientes adultos, é mais difícil, provavelmente devido a baixos títulos de vírus nas secreções de adultos, quando comparados àqueles encontrados em crianças. Já, nas amostras de lavado broncoalveolar e secreção traqueal, a detecção do VSR pelo teste rápido foi mais sensível, semelhante aos resultados observados na detecção deste agente em lavado nasal de crianças imunocompetentes.

A prevenção de infecção por VSR, com a utilização de imunoglobulina hiperimune ("RSV-IGIV Respigam ${ }^{\circledR}$ - Medimmune, Inc.) tem sido eficaz em crianças de alto risco ${ }^{(25)}$, porém esta abordagem não foi sistematicamente testada em adultos. O uso da imunoglobulina anti-VSR deve ser feito durante o período de pico sazonal do vírus ${ }^{(25)}$. Nos países de clima temperado, esta profilaxia tem sido utilizada com aplicações mensais, durante cinco (05) meses, compreendendo o período do final do outono, inverno e início da primavera (novembro a março). Atualmente, também está disponível um anticorpo monoclonal humanizado ("Palivizumab - Synagis ${ }^{\circledR}$ - Abbott, Laboratories")(26) que apresenta vantagens em relação à imunoglobulina anti-VSR, pois não é hemoderivado, e a via de aplicação é intramuscular e com pequeno volume. Este produto foi eficaz na prevenção de hospitalização, em crianças prematuras, quando utilizado em cinco (05) doses durante o período epidêmico em estudo, que envolveu vários centros em países desenvolvidos ${ }^{(26)}$. Uma vacina para VSR ainda não é disponível para uso clínico, porém várias alternativas, em diferentes fases de desenvolvimento, estão sendo testadas ${ }^{27}$.

O ribavirin em aerossol foi eficaz para prevenir a evolução para IRA baixa, quando utilizado, precocemente, nos quadros de IVAS por $\operatorname{VSR}^{(9 ; 27)}$. No entanto, a ribavirina em aerossol ou endovenosa não foi útil no tratamento da pneumonia por VSR, principalmente após a instalação de insuficiência respiratória $^{(9 ; 23)}$. Para esses casos, talvez, possa haver algum benefício na associação de ribavirina em aerossol com o uso de imunoglobulina endovenosa ${ }^{(27)}$. 


\section{VÍRUS PARAINFLUENZA}

Os vírus parainfluenza estão entre os principais agentes de IRA baixa em crianças. $O$ vírus parainfluenza 1 é o agente mais frequiente de crupe e o vírus parainfluenza 3 pode estar presente em quadros de pneumonia e bronquiolite ${ }^{(4)}$.

Wendt et al. ${ }^{(28)}$ estudaram a ocorrência dos vírus parainfluenza em pacientes submetidos a TMO que apresentavam quadro de IRA ou apenas febre. Em um mil duzentos e cinqüenta e três (1253) pacientes, encontraram o vírus parainfluenza por isolamento em 27 (2,2\%). Destes, 19 (70\%) apresentaram sintomas de IRA baixa, sendo que 6/19 (32\%) desenvolveram insuficiência respiratória e evoluíram para óbito.

No estudo de Lewis et al. ${ }^{29}$ no MDACC, $61 / 1173(5,2 \%)$ dos pacientes pós TMO apresentaram infecção por vírus parainfluenza. A freqüência de infecção foi maior em pacientes com transplante alogênico $(8,8 \%)$ em comparação àqueles com transplante autólogo $(3,4 \%)$. Dos casos de infecção por vírus parainfluenza, 36 (59\%) adquiriram a infecção no hospital. Um quadro clínico de IVAS foi observado em 34/61(56\%) casos. Os 27 (44\%) pacientes restantes desenvolveram pneumonia e 10/27 (37\%) destes evoluíram para óbito, que, em nove (09) dos dez (10) pacientes, ocorreu no período de até cem (100) dias após o transplante. Dos pacientes com pneumonia, $85 \%$ apresentaram sintomas prévios de IVAS. Em sete (07) casos submetidos a exame anatomopatológico (uma (01) biópsia pulmonar e seis (06) autópsias), o exame histopatológico revelou achados compatíveis com doença invasiva por vírus parainfluenza em 6/7 (86\%) casos. Outros agentes infecciosos, além de vírus parainfluenza, foram também detectados em sete (07) dos dez (10) pacientes que evoluíram para óbito.

Entre pacientes com leucemia, 6/9 (66\%), todos com mielossupressão, tiveram pneumonia após infecção por vírus parainfluenza. Destes, cinco (05) (80\%) foram precedidos por IVAS e a mortalidade observada foi de $66 \%{ }^{(9)}$.

Em pacientes infectados por HIV, foram relatados casos de infecção respiratória grave, nos quais o vírus parainfluenza 3 foi isolado ${ }^{(30)}$. Porém, outros agentes etiológicos também foram identificados, dificultando a implicação do vírus parainfluenza como causa $^{(30)}$. Nos pacientes, em que somente o vírus parainfluenza foi isolado, a evolução foi, geralmente, de menor gravidade $^{(10,14)}$. Tempo prolongado de excreção viral também foi relatado em casos de infecções por vírus parainfluenza ${ }^{(14)}$.

Não há drogas antivirais de eficácia comprovada para tratar infecções por vírus parainfluenza ${ }^{(27)}$. O uso de ribavirina em aerossol parece beneficiar alguns pacientes, porém outros melhoram sem terapêutica ${ }^{(9,27)}$. Há uma vacina disponível contra o PIV 3, porém esta ainda não foi testada em adultos de alto risco ${ }^{(27)}$.

\section{VÍRUS INFLUENZA}

A gripe, doença causada pelo vírus influenza, é considerada uma das doenças respiratórias mais importantes da humanidade ${ }^{(2)}$. Este vírus apresenta surtos anuais de infecção, com rápida disseminação e acometimento de um grande número de pessoas ${ }^{(31)}$. Está associado a excesso de mortalidade, principalmente em idosos e pacientes com doenças cardiorrespiratórias ${ }^{(31)}$.

Na revisão de Yousuf et al. ${ }^{(32)}$, do MDACC, o vírus influenza foi encontrado em $10-30 \%$ dos pacientes com leucemia pós-TMO, que apresentavam doença respiratória aguda. Da mesma forma que o VSR, o vírus influenza ocorreu com sazonalidade semelhante à observada nas infecções da comunidade. Nesses pacientes, o curso clínico da infecção por vírus influenza foi semelhante ao observado em indivíduos imunocompetentes, iniciando-se com febre, tosse e sibilância. Observou-se complicação com pneumonia, em 75\% dos casos, e a mortalidade associada foi de $40 \%$. Observou-se uma tendência maior para complicações nos pacientes que haviam recebido quimioterapia mais recentemente e naqueles mais mielossuprimidos.

Em oito (08) (80\%) de dez (10) casos autopsiados, em outro estudo de Whimbley et al. ${ }^{(9)}$ os achados histológicos pulmonares foram compatíveis com pneumonia viral, porém em 3/8 (38\%) foram encontrados outros patógenos.

Tratamento precoce com amantadina/rimantadina pode ser benéfico no tratamento de infecções por vírus influenza $\mathrm{A}$, se iniciado precocemente, antes da instalação de insuficiência respiratória ${ }^{(33)}$. No entanto, há descrição de isolamento de vírus influenza resistentes a amantadina de pacientes com leucemia e de pacientes infectados pelo $\mathrm{HIV}^{(34)}$. Inibidores da neuraminidase são eficazes no tratamento de infecção por vírus influenza, tanto $\mathrm{A}$ quanto $\mathrm{B}$, e seu uso pode ser útil em pacientes imunossuprimidos ${ }^{(35)}$. A ribavirina em aerossol não tem sido eficaz no tratamento dessas infecções ${ }^{(33)}$. A utilização da ribavirina endovenosa é ainda investigavél ${ }^{(33)}$. Abordagens terapêuticas mais eficazes para o tratamento de infecções por vírus influenza em pacientes imunodeprimidos ainda são necessárias, e uma delas pode vir a ser associação de drogas antivirais, incluindo inibidores de neuraminidase ${ }^{(33)}$. 
Em adultos infectados por HIV com infecção respiratória, foi observada maior mortalidade por pneumonia, no entanto, não foi possível confirmar associação causal com o vírus influenza ${ }^{(36)}$. Em outro estudo ${ }^{(15)}$, de apenas seis (06) casos, apesar de associar o vírus influenza com casos de IRA baixa, não foi observada maior mortalidade, mas foi registrado curso mais prolongado de doença, que poderia, também, estar associado a maior tempo de excreção prolongada do agente viral, como no caso relatado por Evans et al. ${ }^{(37)}$.

O Centers for Disease Control and Prevention (CDC), Atlanta - Georgia - EUA, recomenda a vacinação anual e/ou quimioprofilaxia para a prevenção de infecção por vírus influenza para os pacientes com imunodepressão ${ }^{(38)}$. No entanto, vacinação contra influenza não tem sido muito adotada nos centros para tratamento de câncer em virtude de acreditar-se que estes pacientes não são capazes de montar uma resposta imune protetora após a vacinação ${ }^{(9,39)}$. Esquemas especiais de vacinação com mais de uma dose podem ser utilizados, e pacientes devem, preferencialmente, ser vacinados antes de receberem quimioterapia $^{(33)}$. Em pacientes infectados por HIV, a vacinação contra influenza pode ser eficaz na prevenção deste $\operatorname{agente}^{(38,40)}$.

\section{RINOVÍRUS}

Os rinovírus humanos (> 100 tipos) são os agentes mais freqüentes de IRA, estimando-se a ocorrência de uma infecção por pessoa, por ano, nos países de clima temperado ${ }^{(41)}$. Naqueles países, a incidência de rinovírus apresenta pico no outono. No estudo do MDACC $^{(9)}$, picornavírus foram isolados de pacientes com câncer, durante todo o ano, porém com aumento de incidência nos meses de outono e inverno. Os autores encontraram um picornavírus em $28 \%$ das amostras positivas para vírus, em um período de três (03) anos, sendo que $90 \%$ deles eram rinovírus. Desde 1991, o mesmo centro de tratamento de câncer documentou aproximadamente cento e trinta (130) episódios de infecção por picornavírus, em adultos com leucemia ou submetidos a TMO, sendo $90 \%$ destes causados por rinovírus. Na maioria dos pacientes, o quadro clínico foi limitado a IVAS ou complicado por pneumonia bacteriana e/ou fúngica. No entanto, alguns casos apresentaram quadro clínico compatível com pneumonia viral e evoluíram para óbito por pneumonia intersticial.

Arola et al. ${ }^{(11)}$ encontraram rinovírus em 13/75 (17\%) episódios febris em crianças submetidas a tratamento para câncer. Esses autores não observaram diferenças de ocorrência deste agente entre pacientes leucopênicos ou não. Todos os casos apresentaram IVAS com evolução clínica satisfatória.

Em pacientes infectados pelo HIV, não há relatos de associação dos rinovírus com IRA não complicada, bem como não foi estudada a duração da excreção deste vírus nas secreções respiratórias ${ }^{(14)}$.

\section{ADENOVÍRUS}

Dentre os vírus respiratórios, os adenovírus têm sido associados a doença de maior gravidade em pacientes imunodeprimidos ${ }^{(42,43)}$. Podem causar quadros de infecção disseminada, cistite hemorrágica, hepatite, encefalite e IRA ${ }^{(43)}$. Adenovírus podem permanecer latentes e, portanto, sua detecção pode dever-se a infecção ou reativação ${ }^{(3)}$.

Shields et al. ${ }^{(44)}$, numa revisão dos pacientes do FHCRC, no período de 1976 à 1982, relataram adenovírus em 51/1051 pacientes submetidos a TMO. Doença invasiva foi confirmada por biópsia ou autópsia em 10/51 (19,6\%) pacientes. O vírus foi isolado do pulmão em dez (10) pacientes e quatro (04) evoluíram para óbito por pneumonia. Além destes, cinco (05) tiveram isolamento de adenovírus do tecido renal e apresentaram sinais de alteração da função renal, do mesmo modo que pacientes com adenovírus isolados do tecido hepático apresentaram quadro de hepatite. A fonte mais provável da infecção foi a reativação de adenovírus latente. $\mathrm{O}$ único fator de risco identificado foi a presença de reação enxerto versus hospedeiro.

Do mesmo modo, Flomberg et al. ${ }^{(45)}$ isolararam adenovírus em quarenta e dois (42) de duzentos e um (201) $(20,9 \%)$ pacientes após TMO. Foi observada maior incidência em crianças, que também apresentaram início mais precoce da infecção (média trinta (30) dias pós TMO). Esses autores também identificaram fatores de risco para doença disseminada, tais como a presença de reação enxerto versus hospedeiro e o isolamento de adenovírus de múltiplos sítios.

No MDACC ${ }^{(9)}$, entre 1991 a 1995, vinte e oito (28) pacientes pós TMO apresentaram cultura de lavado nasal positiva para adenovírus. Destes, 15 (54\%) sobreviveram, sendo dez (10) com IVAS e cinco (05) com pneumonia, e treze (13) (46\%) evoluíram para óbito, dos quais sete (07) com pneumonia e seis (06) com doença disseminada. Diferentemente dos outros agentes citados, a maioria dos casos de pneumonia não foi precidida por IVAS. Os fatores de risco para doença grave também foram o isolamento de adenovírus de múltiplos sítios e presença da reação enxerto 
versus hospedeiro. O uso de ribavirina e imunoglobulina não foi eficaz no tratamento de pacientes com pneumonia, porém, exceto por um caso tratado com ribavirina endovenosa, sua utilização foi tardia.

\section{CORONAVÍRUS}

Os coronavírus são causa comum de IVAS na comunidade $^{(4)}$, no entanto, as dificuldades em isolar esses agentes em amostras clínicas, tornam seu diagnóstico complicado ${ }^{(3)}$. O método de RT-PCR tem possibilitado melhor avaliação da importância desses agentes na comunidade ${ }^{(46)}$, porém, os coronavírus não têm sido sistematicamente investigados em IRAs em pacientes com imunodepressão ${ }^{(9)}$.

\section{COMENTÁRIOS E CONCLUSÕES}

Como foi resumido nesta revisão, pacientes com função imune comprometida parecem ser suscetíveis aos mesmos vírus respiratórios que acometem a população em geral. No entanto, a imunodepressão é potencialmente capaz de criar condições para o surgimento de complicações de quadros clínicos que, normalmente, são leves, em indivíduos imunocompetentes.

O VSR parece ser o principal agente de IRA baixa em pacientes com câncer e nos submetidos a TMO, e a mortalidade associada a esse vírus pode ser elevada nesses pacientes. Ainda não há terapêutica uniformemente eficaz para VSR, porém, a prevenção de quadros graves, pelo uso precoce de ribavirina em aerossol, pode ser eficaz. Desta forma, o diagnóstico precoce deste agente é importante.

Os vírus parainfluenza foram encontrados com menor frequiência, porém, também, têm sido associados a alta mortalidade em imunossuprimidos. A presença freqüente de outros agentes infecciosos, no mesmo paciente, dificulta a associação desses agentes com quadros clínicos de maior gravidade. A eficácia da terapêutica com ribavirina ainda não foi demonstrada e a prevenção com vacina não foi testada nesses pacientes.

$\mathrm{O}$ vírus influenza tem sido relatado com freqüência em pacientes com câncer e em infectados pelo HIV. A mortalidade causada por influenza nos pacientes com neoplasia e nos submetidos a TMO pode ser elevada, fato que não tem sido comprovado em pessoas infectadas pelo HIV. A prevenção com vacina, em esquemas especiais, ou com quimioprofilaxia pode ser benéfica nesses pacientes. O tratamento de infecções por vírus influenza deve ser precoce, pode ser feito com amantadina, rimantadina ou inbidores da neuraminidase, porém, há cepas virais resistentes. Terapêutica com associação de drogas parece ser uma opção para tratamento destas infecções em pacientes imunossuprimidos, reduzindo chances de emergência de vírus resistentes.

Adenovírus tem sido o agente viral, associado a doença disseminada, mais grave, em pacientes imunossuprimidos, principalmente por reativação de vírus endógeno. Em crianças, porém, a infecção primária pode ser mais freqüente do que a reativação da latência. Apesar das tentativas com o uso de ribavirina, não há tratamento eficaz.

Os rinovírus e coronavírus ainda não mostraram muito claramente sua participação em pacientes imunossuprimidos. O rinovírus pode ser, principalmente, um fator predisponente para IRA baixa, causada por outros agentes; no entanto, há casos de infecção por rinovírus que desenvolveram pneumonia intersticial sem que nenhum outro agente tivesse sido isolado. Ainda não se dispõe de terapêutica eficaz para esses vírus. A prevenção do rinovírus com o uso de interferon nasal pode ser eficaz, porém os efeitos colaterais dificultam sua utilização ${ }^{(47)}$. $\mathrm{O}$ tratamento de picornavírus com agentes ligantes de capsídeo (pleconaril) é uma nova perspectiva para o tratamento destes vírus ${ }^{(48)}$.

Em Ribeirão Preto, vem sendo realizado o diagnóstico sistemático dos vírus respiratórios por imunofluorescência indireta e, mais recentemente, por técnicas de PCR. Tais métodos têm permitido identificar infecções respiratórias virais em crianças infectadas pelo HIV e analisar suas características clínicas $^{(49)}$. Nos pacientes HIV positivos, não foram observadas diferenças clínicas nas infecções pelo VSR, quando comparados a uma população de crianças não infectadas pelo HIV ${ }^{(50)}$.

Com base no exposto e conhecendo-se a sazonalidade dos vírus respiratórios, como é o exemplo do VSR em Ribeirão Preto ${ }^{(51)}$, é possível propor estratégias que visem minimizar o impacto de IRA entre pacientes imunossuprimidos, tais como o uso de imunoglobulina para a prevenção do VSR. A disponibilidade de meios diagnósticos rápidos e sensíveis, como a PCR, deve estimular a busca de etiologias virais nas pneumonias de pacientes com função imune comprometida. Além disso, o diagnóstico rápido dos agentes virais, em pacientes hospitalizados, pode reduzir as chances de infecção nosocomial através de medidas preventivas adequadas ${ }^{(52)}$. 
CINTRA OAL \& ARRUDA E. Respiratory viral infections in immunocompromised patients. Medicina, Ribeirão Preto, 32: 129-137, apr./june 1999.

ABSTRACT: Acute infections caused by respiratory viruses are the most frequent infections of mankind. Respiratory viruses that cause common infections in normal hosts have been increasingly recognized as a cause of respiratory infections in immunodeficient patients. This paper briefly reviews clinical and epidemiological aspects of these infections, highlighting their significance in patients with compromised immune function.

UNITERMS: Respiratory Tract Infections. Immunodeficiency. HIV.

\section{REFERÊNCIAS BIBLIOGRÁFICAS}

1 - WORLD HEALTH ORGANIZATION SCIENTIFIC GROUP: Viral respiratory diseases. WHO Technical Report Series, 642. Geneva,1980.

2 - MCINTOSH K; HALONEN P \& RUUSKANEN O. Report of a workshop on respiratory viral infection: epidemiology, diagnosis, treatment, and prevention. Clin Infect Dis 16: 151-164;1993.

3 - COUCH RB; ENGLUND JA \& WHIMBLEY E. Respiratory viral infections in immunocompetent and immunocompromised persons. Am J Med 102(3A): 2-9,1997.

4 - HEMMING VG. Viral respiratory diseases in children: classification, etiology, epidemiology, and risk factors. J Pediatr 124(5):S13-S16,1994.

5 - ARRUDA E; GEIST FC; MCAULIFFE MI \& HAYDEN FG. Viral respiratory tract illnesses in a developing tropical area. Prospective studies in Gonçalves Dias, Fortaleza, Brazil. In: GUERRANT RL; DE SOUZA MA \& NATIONS MK, eds. At the edge of development. Health crises in a transational society. Carolina Academic Press, Durham, North Carolina, p. 203-224, 1996.

6 - CASE RECORDS OF THE MASSACHUSETTS GENERAL HOSPITAL (CASE 31-1996). N Engl J Med 335:1133-1140,1996.

7 - HALL CB; POWELL KR; MacDONALD NE; GALA CL; MENEGUS ME; SUFFIN SC \& COHEN HJ. Respiratory syncytial viral infection in children with compromised immune function. N Engl J Med 315: 77-81, 1986.

8 - JARVIS WR; MIDDLETON PJ \& GELFAND EW. Parainfluenza pneumonia in severe combined immunodeficiency disease. J Pediatr 94: 423-425, 1979.

9 - WHIMBLEY E; ENGLUND JA \& COUCH RB. Community respiratory virus infections in immunocompromised patients with cancer. Am J Med 102(3A):10-18, 1997.

10 - MCINTOSH K. Respiratory virus infections. In: PIZZO PA \& WILFERT C M eds. Pediatric AIDS. The challenge of HIV infection in infants, children, and adolescents. $2^{\text {nd }}$ ed, Williams \& Wilkins, Baltimore, Maryland, p. 365-376,1993.

11 - AROLA M; RUUSKANEN O; ZIELGLER T \& SALMI TT. Respiratory virus infections during anticancer treatment in children. Ped Infect Dis J 14:690-694, 1995.

12 - BOWDEN RA. Respiratory virus infections after marrow transplant: The Fred Hutchinson Cancer Research Center experience. Am J Med 102(3A): 27-30, 1997
13 - WENDT CH. Community respiratory viruses: Organ transplant recipients. Am J Med 102(3A):31-36,1997.

14 - KING JR. JC. Community respiratory viruses in individuals with human immunodeficiency virus infection. Am $\mathbf{J}$ Med 102(3A):19-24, 1997.

15 - SAFRIN S; RUSH JD \& MILLS J. Influenza in patients with human immunodeficiency virus infection. Chest 95: 807810, 1990.

16 - JANNER D; PETRU AM; BELCHIS D \& AZIMI PH. Fatal adenovirus infection in a child with acquired immunodeficiency syndrome. Ped Infect Dis J 9: 434-436, 1990.

17 - MURPHY D \& ROSE RC. Respiratory syncytial virus pneumonia in a human immunodeficiency infected man. JAMA 261: 1147, 1989.

18 - CHANDWANI S; BORKOWSKY W; KRASINSKI K; LAWRENCE $R$ \& WELLIVER R. Respiratory syncytial virus infection in human immunodeficiency virus-infected children. J Pediatr 117:251-254;1990.

19 - KING JR. JC; BURKE AR; CLEMENS JD; NAIR P; FARLEY JJ; VINK PE; BATLAS SR; RAO M \& JOHNSON JP. Respiratory syncytial virus illnesses in human immunodeficiency virusand noninfected children. Pediatr Infect Dis J 12: 733739,1993

20 - WHIMBLEY E; COUCH RB; ENGLUND JÁ; ANDREEFF M; GOODRICH JM; RAAD II; LEWIS V; MIRZA N; LUNA MA; BAXTER B; TARRAND JJ \& BODEY GP. Respiratory syncytial virus pneumonia in hospitalized patients with leukemia. Clin Infect Dis 21:376-379,1995.

21 - WHIMBLEY E; CHAMPLIN RE; COUCH RB; ENGLUND JÁ; GOODRICH JM; RAAD I; PRZEPIORKAD; LEWIS VA; MIRZAN; YOUSUF H; TARRAND JJ \& BODEY GP. Community respiratory virus infections among hospitalized adult bone marrow transplant recipients. Clin Infect Dis 22: 778-782, 1996.

22 - LJUNGMAN P. Respiratory virus infections in bone marrow transplant recipients: The European perspective. Am J Med 102(3A):44-47,1997.

23 - LEVINSOHN DM; BOWDEN RA; MATTSON D \& CRAWFORD SW. Phase I stusy of intravenous ribavirin treatment of respiratory syncytial virus pneumonia after bone marrow transplant. Antimicrob Agents Chemother 40: 2555-2557,1996.

24 - ENGLUND JA; PIEDRA PA; JEWELLA; PATEL K; BAXTER BB \& WHIMBLEY E. Rapid diagnosis of respiratory syncytial virus infections in immunocompromised adults. J Clin Microbiol 34:1649-1653;1996. 
25 - THE PREVENT STUDY GROUP. Reduction of respiratory syncytial virus hospitalization among premature infants with bronchopulmonary displasia using respiratory syncytial virus immune globulin. Pediatrics 99: 93-99,1997.

26 - THE IMPACT-RSV STUDY GROUP. Palivizumab, a humanized espiratory syncytial virus monoclonal antibody, reduces hospitalization from respiratory syncytial virus infection in high-risk infants. Pediatrics 102: 531-537,1998.

27 - ENGLUND JA; PIEDRA PA \& WHIMBLEYE. Prevention and treatment of respiratory syncytial virus and parainfluenza viruses in immunocompromised patients. Am J Med 102(3A):61-70,1997.

28 - WENDT C; WEISDORF DJ; JORDAN C; BALFOUR JR. HH \& HERTZ ML. Parainfluenza virus respiratory infection after bone marrow transplantation. N Engl J Med 326: $921-$ 926;1992.

29 - LEWIS VA; CHAMPLIN R; ENGLUND J; COUCH R; GOODRICH JM; ROLSTON K; PRZEPIORKA D; MIRZA NQ; YOUSUF HM; LUNA M; BODEY GP \& WHIMBLEY E. Respiratory disease doe to parainfluenza virus in adult bone marrow transplant recipients. Clin Infect Dis 23: 1033-1037;1996.

30 - JOSEPHS S; WHA KIM H; BRANDT CD \& PARROT $\mathrm{RH}$. Parainfluenza 3 virus and other common respiratory pathogens in children with human immunodeficiency virus infection. Pediatr Infect Dis J 7: 207-209;1988.

31 - HAYDEN FG. Influenza virus. In: RICHMAM DD; WHITLEY RJ \& HAYDEN FG, eds; Clinical virology. Churchill Livingstone. New York, p. 911-942,1997.

32 - YOUSUF HM; ENGLUND J; COUCH R; ROLSTON K; LUNA M; GOODRICH J; LEWIS V; MIRZA NQ; ANDREEFF M; KOLLER C; ELTING L; BODEY GP \& WHIMBLEY E. Influenza among hospitalized patients with leukemia. Clin Infect Dis 24: 1095-1099,1997.

33 - HAYDEN FG. Prevention and treatment of influenza in immunocompromised patients. Am J Med 102(3A): 55-60,1997.

34 - KLIMOV Al; ROCHA E; HAYDEN FG; SHULT PA; ROUMILLAT LF \& COX NJ. Prolonged shedding of amantadine-resistant influenza A viruses by immunodeficient patients: detection by polimerase chain reaction - restriction analysis. J Infect Dis 172:1352-1355, 1995.

35 - HAYDEN FG; TREANOR JJ; BETTS RF; LOBO M; ESINHAD TD \& HUSSEY EK. Safety and efficacy of the neuraminidase inhibitor GG 167 in experimental human influenza. JAMA 275: 295-299;1996.

36 - CENTERS FOR DISEASE CONTROL. Increase in pneumonia mortality among young adults and the HIV epidemic - New York City, United States. MMWR 37:593-596,1988.

37 - EVANS KD \& KLINE, MW. Prolonged influenza A infection responsive to rimantadine therapy in a human immunodeficiency virus-infected child. Pediatr Infect Dis J 14: 332-334,1995.

38 - CENTERS FOR DISEASE CONTROL. Prevention and control of influenza. Recomendadtions of the Advisory Comitee on Immunization Practices (ACIP). MMWR 45(RR-5):1-26,1996.

39 - GROSS PA; GOULD AL \& BROWN AE. Effect of cancer chemotherapy on the immune response to influenza virus vaccine: review of published studies. Rev Infect Dis 7: 613-618,1985
40 - CHADWICK EG; CHANG G; DECKER, MD; YOGEV R; DIMICHELE D \& EDWARDS, KM. Serologic response to standard inactivated influenza vaccine in human immunodeficiency virus-infected children. Pediatr Infect Dis J 13: 206-211;1994.

41 - ARRUDA E; PITKARANTA A; WITEK, TJ; DOYLE,CA \& HAYDEN FG. Frequency and natural history of rhinovirus infection in adults during autumn. J Clin Microbiol 35: 2864-2868, 1997.

42 - JANNER D; PETRU AM; BELCHIS D \& AZIMI PH. Fatal adenovirus infection in a child with acquired immunodeficiency syndrome. Pediatr Infect Dis J 9: 434-436,1990.

43 - KRILOV LR; RUBIN LG; FROGEL M; GLOSTER E; NI K; KAPLAN M \& LIPSON SM. Disseminated adenovirus infection with hepatic necrosis in patients with human immunodeficiency virus infection and other immunodeficiency states. Rev Infect Dis 12: 303-307;1990.

44 - SHIELDS AF; HACKMAN RG; FIFE KH; COREY LC \& MEYERS JD. Adenovirus infections in patients undergoing bonemarrow transplantation. N Engl J Med 312: 529-533;1985.

45 - FLOMENBERG P; BABBITT J; DROBYSKI WR; ASH RC; CARRIGAN DR; SEDMAK GV; MCAULIFFE T; CAMITTA B; HOROWITZ MH; BUNIN N \& CASPER JT. Increasing incidence of adenovírus disease in bone marrow transplant recipients. J Infect Dis 169: 775-781;1994.

46 - PITKÄRANTA A; JERO J; ARRUDA E; VIROLAINEN A \& HAYDEN FG. Polymerase chain reaction-based detection of rhinovirus, respiratory syncytial virus, and coronavirus in otitis media with effusion. J Pediatr 133: 390-394;1998.

47 - ARRUDA E \& HAYDEN FG. Clinical studies of antiviral agents for picornaviral infections. In: JEFFREIS DJ \& CLERCQ E, eds. Antiviral chemotherapy. John Wiley \& Sons, England. p. 321-356, 1994.

48 - GROARKE JM \& PEVEAR DC. Attenuated virulence of pleconaril-resistant coxsackievirus B3 variants. J Infect Dis 179:1538-1541,1999.

49 - CINTRA OAL; NEGRINI BVM; MUCILLO PHF; LIMA M; LIMA MI; PINHATA MM; ROCHA GM \& FEREZ MC. Infecção respiratória aguda (IRA) viral em crianças HIV positivas: características clínicas. In: Anais X Congresso Brasileiro de Infectologia Pediátrica 15,1996.

50 - CINTRA OAL; CUNHA CSR; MOTAMTO; MACEDO IS; SILVA ML; CERVI MC; ROCHA GM \& ARRUDA E. Respiratory syncytial virus (RSV) in lower respiratory tract infections (LRTI) of hospitalized children with HIV. Virus: Reviews \& Research. In: Annals, IXth National Meeting of Virology, 3(suppl 1):132 H-141,1998.

51 - CINTRA OAL. Ocorrência e gravidade do vírus sincicial respiratório, grupos $\mathrm{A}$ e $\mathrm{B}$, em crianças de 0 a 24 meses de idade atendidas em pronto socorro de pediatria na cidade de Ribeirão Preto - São Paulo. Dissertação de Mestrado, Faculdade de Medicina de Ribeirão Preto 1997.

52 - RAAD I; ABBAS J \& WHIMBLEY E. Infection control of nosocomial respiratory viral disease in the immunocompromised host. Am J Med 102(3A):48-52,1997.

Recebido para publicação em 05/05/99

Aprovado para publicação em 02/06/99 